\title{
Johannes the seducer's diary or the seduced Kierkegaard's diary
}

\section{[El diario de Juan el seductor o de un Kierkegaard seducido]}

\author{
Jose Garcia Martin - Martina Pavlikova - Igor Tavilla
}

DOI: 10.18355/XL.2018.11.02.25

\begin{abstract}
The author addresses a series of problematic questions that arise in any study or research of the Danish philosopher Søren Kierkegaard. These issues concern both the writer and his work. Such issues include, for example, the problem of pseudonyms in the area of communication, with references to his position on knowledge and truth. The purpose here is to present a sophisticated contextual interpretation, from a historical and socio-cultural perspective, of the aesthetic life, modernity and its seduction, with reference to Kierkegaard's The Seducer's Diary. At the same time, the author explores the pseudonym of John the Seducer and the fundamental values in Kierkegaard's works. These include discussion of the "I" or category of individuality, to which Kierkegaard continually refers to his work, as opposed to the impersonal. In this way, both the seducer and the seduced are identified in Kierkegaard's work.

Key words: Kierkegaard, pseudonyms, communication, method, seduction, situation, reduplication, truth

Resumen:

Partiendo introductoriamente de forma problemática de la figura de Kierkegaard como escritor y su obra, se aborda una serie de cuestiones involucradas en cualquier estudio o investigación sobre el pensador danés. Desde el problema de los pseudónimos hasta principalmente el de la comunicación, pasando por el del conocimiento y la verdad. El propósito es presentar una compleja interpretación, desde una perspectiva contextual histórica y socio-cultural, de la vida estética o lo estético, la modernidad y su seducción, al hilo del Diario de un seductor de Kierkegaard. Al mismo tiempo se indaga en el pseudónimo de Juan el Seductor y en el valor fundamental en Kierkegaard del "yo" o categoría de la individualidad, a la cual remite constantemente Kierkegaard en su obra, frente a lo impersonal. De alguna forma, lo seductor y lo seducido se identifican en Kierkegaard.
\end{abstract}

Palabras clave: Kierkegaard, pseudónimos, comunicación, método, seducción, situación, reduplicación, verdad

\section{Introducción}

"Nada hay que pueda concentrar sobre sí tanta seducción y maldición como un secreto"

Kierkegaard, 1976: 192

Uno puede vivir de muchas maneras, pero no todas son igualmente valiosas. $\mathrm{Ni}$ todas pueden ser vividas simultáneamente de forma auténtica y apasionada. A no ser que nos recreemos en la fantasía, la imaginación artística, o los recuerdos revividos. De igual manera, ninguna de ellas puede experimentarse más que individualmente; yo solo puedo vivir y experimentar mi vida, no la de los demás. No obstante, puedo reconocer vidas no vividas, sentir alegría o tristeza, e incluso extraviarme rememorando aquello que pudo haber sido y no fue. $\mathrm{O}$ puede ser que renazca constantemente, recreándome literaria o artísticamente por mi no-yo, por mi continuo fallecer y desfallecer existencial. El sentido de la fugacidad solo puede 
provenir de una conciencia eterna. Asirla, exponerla, relatarla y narrarla fue básicamente la tarea kierkegaardiana.

Kierkegaard no sería Kierkegaard (ni se le conocería) sin su obra; pero su obra no se entendería sin su contexto histórico-cultural, ni sin sus circunstancias existenciales. Por ello, la comprensión de su existencia como individuo, su biografía particular, se convierte en clave hermenéutica (si bien no es la única), no solo para los lectores de su obra, sino para él mismo. Se trata, pues, de una labor de descubrimiento, pero también de auto-desvelamiento que hace Kierkegaard respecto a sí mismo y el sentido que tiene su existencia (SKP, I A 75/SKS, AA: 12). Como sabemos, tal sentido fue el religioso cristiano. La dificultad se encuentra en que, al menos inicialmente, el problema es que él mismo es el problema. No hay distanciamiento ni puede haberlo. Y no puede haberlo porque sencillamente se trata de "su" problema existencial, no uno científico al caso. Precisamente, se puede entender la diversidad de pseudónimos de su obra como un modo de distanciarse de sí mismo, de proyectarse creativamente en diversas individualidades; individualidades, cada una, con su propio perfil psicológico e intelectual.

\section{El problema de la pseudonomía}

Dichos pseudónimos representarían "avatares", en el sentido de referirse a diversas circunstancias personales; a este respecto, El diario de un seductor fue escrito para Regina, por su bien, para deshacerse de ella (SKP, X I A 266/SKS, NB10: 185). De alguna forma, Kierkegaard trató de justificar su ruptura con ella; ante sí mismo y ante ella. Por ello, siguiendo a J. Garff (2017), podríamos afirmar que Regina fue la musa inspiradora de Kierkegaard. Por otro lado, podríamos afirmar que los pseudónimos son como "yoes" virtuales (o encarnaciones) asumidos por el propio Kierkegaard; como personajes de una representación teatral, o pintadas de un cuadro que elaboró artísticamente sobre el lienzo vacío de su destino.

Pero los pseudónimos kierkegaardianos no son solamente "proyecciones", sino también "evocaciones". Evocan lo vivido (o lo por vivir), probablemente tanto de forma existencial y biográfica, como idealizada. En ese sentido, el impulso erótico (e incluso romántico), representó el punto de partida de la obra kierkegaardiana. Precisamente, ese sería la función de Juan el Seductor: "Joh[annes]. Forføreren det reent sandselige Moment i Forhold til Er[otik]."/" Juan el Seductor es el puro aspecto sensual en relación con lo erótico" (SKP, V A 110/SKS, JJ: 118). Cual dialéctica platónica, Kierkegaard se elevó al conocimiento de lo máximamente real y auténtico: al mundo transcendente y trascendental de la existencia y naturaleza humanas; a partir de la suya propia y por sí mismo (aunque no para sí mismo solo). Asciende por una "escala celestial", más allá de lo puramente factual y sensorial; pero como esclavo "liberado" de las cadenas terrenales, feliz y contento por su descubrimiento, desciende asiduamente a nuestra prisión para advertirnos de nuestra ignorancia y engaños. En esa lucha gastó su vida y labor productora. Como Sócrates, Kierkegaard apeló al auténtico sentido de la existencia humana y al individuo; y como él, no le importó sucumbir bajo el peso de la iniquidad y la injusticia.

Por otro lado, y recurriendo a uno de los conceptos kierkegaardianos más importantes, podríamos calificar a los pseudónimos como reduplicaciones literarias (aunque no existenciales, es decir, auténticas) de modelos o arquetipos de individualidades pensados y/o vividos en cierta manera por el propio Kierkegaard. Con ello pretendió enfatizar el valor de la existencia personal frente a la impersonal. Son, además, el testimonio escrito de un pensamiento existencial y de una existencia reflexionada inquisitivamente.

Las interpretaciones que caben dar a los pseudónimos son múltiples y no existe una unanimidad entre los estudiosos de cuál es su significado. En mi opinión, dicho significado es múltiple y diverso. Por tanto, no debemos ser de ninguna manera

XLinguae, Volume 11, Issue 2, April 2018, ISSN 1337-8384, eISSN 2453-711X 
reduccionista o excluyente a la hora de proponer alguna interpretación. En el caso de Johannes (Juan) el Seductor, Dewey ha presentado hasta siete interpretaciones de este pseudónimo (Dewey, 1995: 159-199). Quién es Johannes y qué pretendió Kierkegaard comunicar con esta figura, es algo bastante controvertido. De entre ellas, me parece evidente interpretarlo fácilmente como clave para conocer el Kierkegaard real (su juventud) y para darnos pistas sobre la relación con Regina (Dewey, 1995: 169-171). Por otro lado, parece clara la influencia del romanticismo en este pseudónimo, y su interpretación como un artista también es lógica. Con esta figura estética, Kierkegaard parece querer retratar la vida estética como asidero a una vida sin sentido, de falta de autoconciencia, contra la desesperación y el aburrimiento (Dewey, 1995: 195). Podríamos afirmar que Kierkegaard, antes que Nietzsche, supo prever las consecuencias de una vida sin Dios (Dewey, 1995: 192). En cualquier caso, la figura de Johannes el Seductor es clave para entender el significado de lo estético.

\section{El problema de la comunicación en Kierkegaard}

Podríamos afirmar que la obra de Kierkegaard surgió de la necesidad desbordante de comunicar (y de comunicarse) un mismo mensaje personal, pero de dos maneras distintas. Ese mensaje es el de tomarse en serio y responsablemente nuestra existencia individual, cristianamente hablando. Y lo hace tanto directa como indirectamente. Su estrategia, pues, es doble. Directamente, a través de su obra "verónima" (obras firmadas con su propio nombre); e indirectamente, a través de la obra pseudónima. A la comunicación directa la denomina Kierkegaard comunicación de saber; mientras que la segunda se trata de una comunicación de poder.

No podemos soslayar el problema de la comunicación en Kierkegaard (García Martín \& Giordano, 2011: 9-12). Es más, de alguna forma hay que tomar posición al respecto; incluso antes de cualquier otro estudio sobra la obra y el pensamiento kierkegaardiano. En ese sentido, es difícil de fundamentar (por no decir imposible) suficientemente una investigación kierkegaardiana sin abordar previamente dicho problema. Por otro lado, tampoco sería serio un estudio en el que ni siquiera se distinguiera entre los diversos pseudónimos kierkegaardianos entre sí, y de estos con respecto a Kierkegaard mismo. Podríamos caracterizar al insigne danés como un romántico, un idealista o hegeliano, un postmoderno, un pensador existencial, una persona infeliz o melancólica, un cristiano riguroso, un aristócrata burgués y conservador, el hijo mimado de su padre, un estudiante "juerguista" y amante de las fiestas, un desalmado y canalla amante... Pero habría que adjetivar o precisar en qué sentido y con respecto a qué; por tanto, con qué comunicación y figura lo expresa o manifiesta. Si no se hace así, corremos el riesgo grave de contradecirnos; de afirmar y negar a la vez lo mismo y al mismo tiempo (por ejemplo, que Kierkegaard fue y no fue un idealista; o bien, que fue y no fue un pensador cristiano). Así pues, habría que hablar de un Kierkegaard Don Juan, de un Kierkegaard religioso, o de un Kierkegaard Johannes de Silentio, por ejemplo. Asimismo, resulta imprescindible contrastar y comparar las diversas partes de su obra escrita entre sí; así como de esta con sus diarios y demás papeles no publicados. A este respecto, creo honestamente que no se debe olvidar el sentido de su obra en general, del mismo modo que la tremenda importancia de sus diarios como criterio discriminador privilegiado; aunque no necesariamente único.

\section{La cuestión del método}

Como es sabido, el problema del método es un problema moderno. Es el problema epistemológico por antonomasia. La modernidad se centró, no tanto en el conocimiento de la realidad, cuanto si este es posible. Hasta tal punto, que la realidad se redujo al conocimiento de ella: la realidad lo es en cuanto que es conocida por el sujeto del conocimiento. La cuestión del método adquirió relevancia en la medida en que se puso el acento en la búsqueda de la certeza y la seguridad cognoscitiva. Al 
mismo tiempo, se produce la revolución científica que dio lugar a la ciencia moderna, paradigma del verdadero conocimiento, basado en un nuevo método que conjuga la observación rigurosa con la razón metódica y apodíctica, prescindiendo de todo aquello que no fuera explicable en términos cuantitativos y matemáticos. Si en el campo científico se pasó del estudio metafísico al positivo de la naturaleza, en el filosófico se produjo una inmanentización o subjetivación, en el que del realismo más o menos ingenuo, se pasó al idealismo. Sea como sea, lo relevante es que la comunicación se vuelve objetiva e impersonal: "Los modernos - y ahí radica uno de sus errores fundamentales más graves- han suprimido la personalidad, y lo han convertido todo en objetividad. No se pierde el tiempo en aclarar lo que es la comunicación, sino que se pasa rápidamente a lo que se quiere comunicar" (Kierkegaard, 2017: 90).

Para Kierkegaard, en cambio, la pregunta o cuestión básica es otra: qué es comunicar; qué significa comunicar; en qué consiste y qué tipos de comunicación existen. De ello depende el método. Sobre todo, cuando lo que tratamos no son temas científicos, sino éticos o religiosos. Porque lo que realmente le importa es la persona, su individualidad y existencia. El problema se presenta cuando se quiere comunicar cuestiones éticas o religiosas como si fueran científicas; esto es, objetivamente, en vez de forma personal o subjetiva. Lo cual provoca una gran confusión en el campo éticoreligioso. El conocimiento científico, no solo es objetivo, sino además intersubjetivo. De ahí la tremenda importancia que adquiere este a partir de la época moderna. Kierkegaard fue plenamente consciente de ello.

El modo kierkegaardiano de enfrentarse a su realidad y expresarla podríamos calificarla como "subjuntivo". No solo porque hace de la propia subjetividad, suya y ajena, el eje de sus reflexiones; sino porque se sirve de lo fantasioso, lo imaginario o irreal, como instrumento privilegiado de comunicación en su obra estética. El propio descubridor del diario de Juan el Seductor, así parece apuntarlo cuando afirma que "su diario (...) no encierra la exactitud de un relato histórico, ni tampoco es una mera narración poética. No está redactado en modo indicativo, sino subjuntivo" (Kierkegaard, 1976: 183).

\section{La seducción de la época moderna}

El predominio del paradigma del conocimiento científico en todos los ámbitos del saber humano tuvo unas consecuencias negativas que, en el caso de la filosofía y según Kierkegaard, produjo una confusión tremenda en la modernidad. Si el "ojo" de la época es la ciencia, con el que todo se conoce, se valora y aprecia de forma confusa, aquella es irremediable y la desorientación inmensa. La consecuencia es la deslealtad o deshonestidad en la que, según el escritor danés, estaba inmersa su época (Kierkegaard, 2017: 42). Dicha falta de lealtad u honestidad (o lo que es lo mismo, de inocencia) hay que entenderla en el sentido de vivir en un continuo autoengaño, el cual hace imposible tanto el engaño deliberado, como la propia verdad. Consecuencia: La responsabilidad personal y la autenticidad se hacen imposibles, suprimiendo de este modo la categoría de individualidad sustituyéndola por la de generación.

Toda la filosofía moderna surgió de un malentendido y una deshonestidad, según se deduce de la lectura del Johannes Climacus o del dudar de todas las cosas de Kierkegaard (Kierkegaard, 2007). Un malentendido, porque lo que era estricta y esencialmente personal (Descartes), se generalizó y se convirtió en un principio y reflexión universal. En segundo lugar, porque se comete una petitio principii; esto es, Descartes presupone ontológicamente lo que quiere demostrar gnoseológicamente (el cogito). Y surge, además, de una deshonestidad, en el sentido de que, a pesar de su actitud radical, Descartes no es capaz de llevar su duda hasta las últimas consecuencias. Duda que no pasa de ser teórica, pero no práctica y existencial.

XLinguae, Volume 11, Issue 2, April 2018, ISSN 1337-8384, eISSN 2453-711X 
Por otro lado, con el pensamiento moderno se plantea el problema de un comienzo absoluto de la filosofía (Kierkegaard, 2007: 58). No obstante, dicho comienzo no es posible, porque al menos se presupone la existencia de aquel que comienza a dudar. En cualquier caso, la cuestión de haberse considerado a la duda el comienzo de la filosofía moderna, representa un auténtico problema. Porque parece que toda filosofía, para ser legítima, debe comenzar con la duda; algo que se demuestra falso, ya que se habla de Filosofía Antigua para diferenciarla de la moderna. Si el comienzo de toda filosofía fuera como la de la moderna, es decir, la duda, entonces no sería simplemente un calificativo histórico. Significaría algo más de lo que significa en realidad. La conclusión obvia es que o bien estamos hablando de distintos tipos de filosofías, lo cual implica que esta no posea ningún contenido esencial, o bien que la Filosofía Moderna no es tal filosofía, sino una receta de cocina la que se le ha cambiado los ingredientes principales para que cada cual la "digiera" a su gusto.

Honestidad y autenticidad, pues, es lo que requiere la modernidad. Dicho requerimiento (o la falta de ello) la asocia Kierkegaard al concepto de "primitividad" (Primitivitet). Ser primitivo significa ser auténtico y "espíritu” (Aand), relacionándose individualmente con la verdad; implica ser un individuo singular. Rechazar la primitividad, sacrificarla en aras a la comodidad de la época y la aprobación de la generación, es tan execrablemente inhumano como "la madre que hace abortar el fruto de sus entrañas" (Kierkegaard, 2017: 51). Precisamente, el remedio para la confusión referida es la "primitividad" y el "individuo singular" (den Enkelte).

\section{Comunicación y verdad}

El tema de la verdad resulta ineludible cuando se trata el del conocimiento. Este, a su vez, está implicado en el de la comunicación. Cuando hablamos de conocimiento, y no simplemente de opinión o creencia, inmediatamente se entiende que es verdadero. Un conocimiento que no fuera verdadero no sería un auténtico conocimiento. Ahora bien, no todo conocimiento verdadero requiere el mismo tipo de comunicación; dependiendo de cuál, esta puede ser apropiado o no. Precisamente, este es el aspecto central para Kierkegaard.

Por otro lado, todo conocimiento (verdadero o que se considere como tal, socialmente hablando) posee un carácter relacional y una triple dimensión: cognoscitiva, lingüística y onto-lógica. Si analizamos con detenimiento la cuestión, ese carácter relacional apunta siempre a dos elementos. Dependiendo de cuáles son y cómo se entienda, las relaciones serían: a) de correspondencia o adecuación (lo real, lo aparente o lo factual con respecto a lo ideal o el ser); b) de congruencia (del "logos" consigo mismo o intralógica); c) de coherencia (de la existencia individual con respecto al ideal ético-religioso); d) de consenso (del "logos" consigo mismo o interlógica o dialógica). En cada uno de los casos se apunta a una clase distinta de verdad: a) ontológica (metafísica) y epistémica (científica u objetiva); b) formal o de corrección; c) existencial (ético-religiosa); d) socio-política (convencional o pragmática).

Pues bien, Kierkegaard apeló a la verdad existencial o ético-religiosa (también denominada subjetiva), en la que se pone en juego nuestra propia existencia y el sentido que esta tiene (Guerrero Martínez, 2004: 32-33). No solamente esto, sino que cabe descubrir implícitamente un sentido "metaético" de la verdad en su obra que permite un tratamiento interdisciplinar (Mahrik, 2018).

\section{Situación y reduplicación}

Según Kierkegaard, el reconocimiento de la verdad ético-religiosa requiere de una determinada situación (Kierkegaard, 2017: 67) en la que se pueda producir la comunicación de su verdad existencial. Dicha situación está referida al modo o la forma en la que se comunica dicha verdad. Y ello es posible gracias a la 
“reduplicación” (Fordoblense) (Kierkegaard, 2017: 68). Precisamente, podríamos considerar a la obra pseudónima como creaciones literarias de situaciones en las que se trata de transmitir un mensaje existencial. Dicho mensaje existencial puede ser diverso: estético, ético y religioso; por tanto, también el tipo de comunicación requerida. En cualquier caso, lo decisivo es la reduplicación existencial.

La reduplicación tiene que ver, pues, con la comunicación; con la comunicación de la verdad existencial. De tal manera que debemos expresarla de la única forma realmente auténtica o más verdadera: con mi propia existencia, porque la realizamos con nuestra vida. Soy yo mismo, con mi existencia, el que comunica y, al mismo tiempo, lo comunicado. El medio y el objeto a la vez. Sin un "yo" no sería posible transmitir tal tipo de conocimiento, no teórico sino práctico. En ese sentido, los pseudónimos representan literariamente esos "yoes" o individuos que tratan, cada uno a su manera, ponernos ante una situación existencial concreta; como en el caso del seductor Juan. Podemos encontrar en La dialéctica de la comunicación ética y ético-religiosa un texto muy significativo:

"Una de las desgracias del mundo moderno está en la supresión del «Yo», del yo personal; justamente por eso, la comunicación ético-religiosa ha desaparecido del mundo. Pero la verdad ético-religiosa se relaciona básicamente con la personalidad; no puede ser transmitida de otra forma sino de un «Yo» a otro «Yo». En la medida en que la comunicación se convierte en objetiva, la verdad se transforma en no-verdad. Es hacia la personalidad donde tenemos que ir. Tengo el mérito de haber introducido personalidades ficticias (mis pseudónimos) que dicen «yo», y así he contribuido, en la medida de lo posible a que mis contemporáneos se esfuercen en escuchar de nuevo un «yo», un Yo personal (no aquel puro y fantástico yo y su ventriloquia)" (Kierkegaard, 2017: 83).

Ahora bien, eso no significa que sea el hombre la "instancia suprema" de la comunicación de la verdad. Según el escritor danés, esa ha sido una confusión fundamental de la modernidad. La única instancia suprema y válida para la comunicación de la verdad ético-religiosa es Dios (Kierkegaard, 2017: 73-74. El hombre solo puede aspirar a imitarle y comunicarla existencialmente. Pero para ello necesita "primitividad" (Primitivitet); esto es, autenticidad y espiritualidad.

\section{Comunicación de saber (Videns Meddelelse) y comunicación de poder (Kunnens Meddelelse)}

El hombre moderno, gracias al desarrollo científico, lo ha reducido todo al conocimiento y la comunicación objetivos. También lo ético-religioso; es decir, el campo existencial y subjetivo. Le interesa más el objeto del mensaje (teórico) que el quién (persona o individuo). Lo cual ha producido una gran confusión por la tergiversación de lo ético-religioso, ya que este ámbito exige otro tipo de tratamiento y comunicación. El conocimiento objetivo, científico, teórico, requiere una comunicación directa; el conocimiento ético-religioso, en cambio, la comunicación indirecta, subjetiva. Pero entonces ¿qué es comunicar?

Podríamos afirmar que es una actividad en la que se transmite un conocimiento (mensaje o información) por parte de una persona hacia otra persona a través de un medio o de una forma determinada. Según Kierkegaard, en el hecho de la comunicación están presentes cuatro aspectos o elementos: a) el objeto (Gjenstanden), b) el emisor (Meddeleren); c) el receptor (Modtageren); y d) la comunicación (Meddelelsen) (Kierkegaard, 2017: 96-97). Dependiendo del énfasis que se ponga en cada uno de estos elementos, tendríamos diferentes maneras de entender el hecho de la comunicación. Sin embargo, para el insigne escritor danés, habría una distinción clave: "se reflexiona o bien sobre el objeto, o bien sobre la comunicación" (Kierkegaard, 2017: 97). En el primer caso, tendríamos una reflexión de saber; en el segundo, de poder. El problema es que el "pensamiento moderno consiste justamente

XLinguae, Volume 11, Issue 2, April 2018, ISSN 1337-8384, eISSN 2453-711X 
en querer considerar solo lo que se debe comunicar, y no lo que es comunicar" (Kierkegaard, 2017: 97). Por tanto, la modernidad ha entendido todo el conocimiento en la forma de comunicación de saber. Incluido, insisto, aquello que se escapa o resulta irreductible a ello: el campo ético y ético-religioso. Ese ha sido otro gran error, porque dichos ámbitos requieren una comunicación de poder (al menos, principalmente).

Ahora bien, la comunicación de poder es triple. Podemos hablar de una comunicación de poder estético, ético y religioso (Kierkegaard, 2017: 99-100). La primera tiene que ver con la enseñanza de algún arte, en el que el emisor y el receptor están a la misma altura (comunicación de poder, en sentido general). Cuando la comunicación gira en torno al receptor, tendríamos el segundo caso: la comunicación de poder-deber; el emisor no es lo más importante, y su función sería la de servir de estímulo para la realización del receptor. Por último, tenemos una comunicación ético-religiosa (o cristiana), cuando se da un momento inicial y transitorio de la simple comunicación de saber hacia la comunicación de deber-poder.

\section{Conclusiones}

En la actualidad, la importancia de lo estético queda meridianamente claro con la omnipresencia de la imagen y el "marketing" en todos los ámbitos de la vida humana. En realidad, todo está condicionado por ello. E igual que en la época de Kierkegaard, resulta relevante plantearse qué significa ser un yo en este contexto. Lo estético, pues, es una categoría importante que conviene no olvidar: "As such, the aesthetic is an important category to think about how humans ask, converse, and answer the question of what it means to be a self" (Jothen, 2014: 6).

Por otro lado, podríamos entender la seducción estética en general, o la de Juan el Seductor en particular, como una comunicación de poder estético: la enseñanza del arte de seducir, en la que se pretende o apunta a una comunicación de poder ético y, en último término, de poder ético-religioso. Pero lo plantea Kierkegaard de manera sugerente e indirecta, incluso subrepticia, para "atrapar" al lector artística o literariamente y poder llevarlo a lo ético y religioso cristiano, en último lugar.

Kierkegaard, pues, evoca también lo posible en forma de imágenes, deseos y sentimientos. Como Juan el Seductor. Y en eso consiste básicamente su "seducción". La seducción de Don Juan se encuentra en ello. Ese es precisamente el "ídolo" de la vida estética. El dios de la fantasía, la imagen romántica y el modelo mismo del seductor. La seducción de Kierkegaard se halla en su capacidad de hacernos imaginar que lo posible puede ser real. Y lo llevó a cabo de forma indirecta y sugerente: seduce porque sugiere. Kierkegaard se revela en tanto que se oculta, y se oculta en lo que revela (como el viejo Heráclito y el dionisíaco Nietzsche). Esa idea seductora lo fue también para Kierkegaard en la misma medida en que el seductor Kierkegaard fue, a su vez, un seducido. Seducido por el mismo anhelo de eternidad y espiritualidad que descubrió en su propia alma humana, en cierta manera desdichada pero al mismo tiempo feliz y bienaventurada.

\section{Bibliographic references}

DEWEY, B. R. 1995. Seven Seducers: A Typology of Interpretations of the Aesthetic Stage in Kierkegaard's "The Seducer's Diary". En R. L. Perkins, Either/Or, (pág. 294). Macon: Mercer University Press.

GARCIA MARTIN, J. - GIORDANO, D. (Edits). 2011. Kierkegaard y la comunicación. Nápoles: Orthotes Editrice.

GARFF, J. 2017. Kierkegaard's Muse. The Mystery of Regine Olsen. Princeton: Princeton University Press.

GUERRERO MARTINEZ, L. I. 2004. La verdad subjetiva. México: Universidad Iberoamericana. 
JOTHEN, P. 2014. Kierkegaard, Aesthetics, and Selfhood. Farnham/Burlington: Ashgate Publishing.

KIERKEGAARD, S. A. 1976. Diario de un seductor. Temor y temblor. (D. Guiérrez Rivero, Trad.) Madrid: Guadarrama.

KIERKEGAARD, S. A. 2007. Johannes Climacus o el dudar de todas las cosas. (P. C. Dip, Trad.) Buenos Aires: Editorial Gorla.

KIERKEGAARD, S. A. 2017. La dialéctica de la comunicación ética y éticoreligiosa. (J. García Martín, Trad.) Barcelona: Herder.

Søren KIERKEGAARDS Papirer (SKP) 1968-1978. Segunda edición ampliada por Niels Thulstrup. Tomos I-XVI. Copenhague: Gyldendal. [1909-1948].

Søren KIERKEGAARDS Skrifter (SKS) 1997-2013. Edición a cargo de Niels Jørgen Cappelørn, Joakim Garff, Johnny Kondrup, Tonny Aagaard Olesen y Steen Tullberg. Tomos 1-28. Copenhague: Gads Forlag.

KONDRLA, P. - KRALIK, R. 2016. The specifics of mission of the thessalonian brothers and the potential for their actualization. Konstantinove Listy, vol. 9, n. 2, pp. 90-97. ISSN 1337-8740.

KRALIK, R. 2017. Kierkegaard's interpretation of faith. In: XLinguae, vol. 10, n. 3, 2017, pp. 37-44. ISSN 1337-8384.

KRALIK, R. - TINLEY, S. J. 2017. Kierkegaard's Ethics as an Answer to Human Alienation in Technocratic Society. In: Komunikacie, vol. 19, n. 1, pp. 25-29. ISSN 1335-4205.

MAHRIK, T. 2108. Truth as the Key Metaethical Category in Kierkegaard. In: XLinguae, vol. 11, n. 1, pp. 40-48. ISSN 1337-8384.

MAHRIK, T. 2015. Kierkegaard's existential ellipse of truth. In: European Journal of Science and Theology, vol. 11, n. 4, pp. 43-52. ISSN 1841-0464.

VALCO, M. - BOEHME, A. J. 2017. Christian Faith and Science: Can Science Enhance Theology? In: European Journal of Science and Theology, vol. 13, n. 3, pp. 8997. ISSN 1841-0464.

VALCO, M. - KRALIK, R. - BARRETT, L. 2015. Moral implications of Augustine's Philosophical and Spiritual Journey in his Confessiones, In: Komunikacie, vol. 17, n. 2, pp. 103-108, ISSN 1335-4205.

VAlCOVA, K. - PAVLIKOVA, M. - ROUBALOVA, M. 2016. Religious existentialism as a countermeasure to moralistic therapeutic deism. In: Komunikacie, vol. 18, n. 3, pp. 98-104. ISSN 0341-2059.

ZALEC, B. 2017. Preferential and non-preferential love in light of Kierkegaard's thought. In: European Journal of Science and Theology, vol. 13,n.2, pp. 179-189. ISSN 1841-0464.

ZALEC, B. 2014. Nazism and Stalinism in the light of Kierkegaard's thought. In: Filozofia, vol. 69, n. 5, pp. 443-450. ISSN 0046-385X.

Words: 4613

Characters: 29583 (16,43 standard pages)

Prof. Dr. José García Martín, PhD.

University of Granada, Department of Sociology,

Faculty of Political Sciences and Sociology,

Calle Rector López Argüeta s/n, 18001 Granada,

Spain

jgarciamartin@ugr.es

XLinguae, Volume 11, Issue 2, April 2018, ISSN 1337-8384, eISSN 2453-711X 
PhDr. Martina Pavlikova, PhD.

Faculty of Arts,

Constantine the Philosopher University in Nitra,

Hodzova 1, 94901 Nitra.

Slovakia

mpavlikova@ukf.sk

Dr. Igor Tavilla, PhD.

Dipartimento di Discipline Umanistiche, Sociali e delle Imprese Culturali University in

Parma. Via D'Azelio, 85 - 43100 Parma.

Italy

igortavi@libero.it 